\title{
Detection of parvovirus B19 in macerated fetal tissue using in situ hybridisation
}

\author{
C Walters, D G Powe, C J H Padfield, D G Fagan
}

\begin{abstract}
Aims-To compare the application of a non-radioactive in situ hybridisation (ISH) technique with an immunocytochemical technique for the detection of human parvovirus B19 in formalin fixed, paraffin wax embedded sections of macerated fetal tissue.

Methods-Archived samples of liver, lung or kidney from 19 human fetuses were investigated for parvovirus B19 using a full length digoxigenin labelled DNA probe of $5.5 \mathrm{~kb}$; bound probe was detected using an anti-digoxigenin (alkaline phosphatase) conjugate and visualised using NBT/BCIP. Immunocytochemical detection of parvovirus B19 was performed using a monoclonal mouse antiparvovirus B19 antiserum, with a streptavidin-biotin complex (horse radish peroxidase) method. Cases were selected to provide a range of diagnostic certainty and a range of degrees of macerative degeneration.
\end{abstract}

Results-Parvovirus B19 was found in 15 of 19 cases using the B19 ISH technique compared with 8 of 19 cases using the immunocytochemical technique. The four negative cases were all controls known to be parvovirus B19 free. All ISH positive cases showed excellent staining with low background regardless of extent of maceration and tissue type. In comparison, sections stained by the immunocytochemical method showed considerable non-specific immunoreactivity in many cases, particularly with severe maceration. Kidney and lung tissues gave the cleanest results.

Conclusions-ISH is more effective than the immunocytochemical technique for the detection of human parvovirus B19 in macerated fetal tissue. The lack of detectable background staining with the ISH technique led to easier interpretation suggesting that this technique should be the method of choice for the investigation of parvovirus $B 19$ in macerated postmortem tissues.

(F Clin Pathol 1997;50:749-754)

Keywords: parvovirus B19; immunochemistry; in situ hybridisation

Human parvovirus B19, recently reclassified to a new genus called Erythrovirus, ${ }^{1}$ is a well characterised, small, non-enveloped DNA virus, which has a single stranded genome of $5.5 \mathrm{~kb}^{2}$
Parvovirus B19 has an affinity for rapidly replicating cells, in particular erythroid progenitor cells (erythroblasts ${ }^{3}$ ) suggesting bone marrow of adults and fetal liver are the major replication sites.

Previous studies have shown parvovirus B19 to be associated with many pathological conditions, ${ }^{4-6}$ including aplastic crises associated with sickle cell anaemia, acute arthritis and arthralgia, and erythema infectiosum. Parvovirus B19 has also been shown to cross the placenta and infect the fetus causing stillbirths, ${ }^{78}$ spontaneous miscarriage, and congenital abnormalities, although there is evidence to suggest that fetal infection with the virus is not always fatal. ${ }^{8}$ It has also been implicated in the development of non-immune hydrops fetalis ${ }^{9}$ where the risk of fetal death was estimated at $9 \%$ in a study of women who had parvovirus B19 positive serology during their pregnancy. ${ }^{10}$

The ability to detect directly parvovirus in macerated tissues using immunologically based techniques is problematic because of degradation of viral surface proteins. Morphological evaluation of severely macerated host tissue is also problematic because of the lysis of nuclei during autolytic processes impairing light microscopic detection of viral inclusion bodies. There is evidence that nucleic acids survive postmortem changes for lengthy periods ${ }^{11}$; therefore, it is conceivable that the viral genome, which is capable of surviving for extended periods of time postmortem, may offer an improved detection method in macerated fetuses. In this study, we compared the application of a non-radioactive in situ hybridisation technique (ISH) with an immunocytochemical technique for the detection of parvovirus $\mathrm{B} 19$ in sections of macerated fetus.

\section{Methods}

CASE SELECTION

Nineteen cases from 1991-96 (gestational age range 12 weeks to full term) were selected from formalin fixed, paraffin wax embedded material archived in the histopathology division of the University Hospital in Nottingham. The cases were selected to reflect a range of diagnostic certainty, and a range of degrees of macerative degeneration. The ISH and immunocytochemistry results were scored blind without knowledge of the clinical status of the case. Details of all cases are summarised in table 1 .

Cases 1 to 4 were positive controls, with recognisable typical diagnostic inclusions in the tissue stained with routine haematoxylin and eosin. 
Table 1 Immunochemical and in situ hybridisation results for fetal tissues

\begin{tabular}{llllllll}
\hline $\begin{array}{l}\text { Case } \\
\text { number }\end{array}$ & $\begin{array}{l}\text { Gestational age } \\
\text { (weeks) }\end{array}$ & $\begin{array}{l}\text { Extent of } \\
\text { maceration }\end{array}$ & Clinical details & Tissue type & $\begin{array}{l}\text { Presence of VI } \\
\text { bodies }\end{array}$ & $\begin{array}{l}\text { Immuno } \\
\text { results }\end{array}$ \\
\hline 1 & 23 & + & Hydrops & Kidney & Yes & +++ & + \\
2 & 14 & + & Hydrops & Liver & Yes & +++ & ++ \\
3 & 14 & ++ & Macerated & Liver & Yes & +++ & + \\
4 & 25 & + & Hydrops & Liver & Yes & +++ & 0 \\
5 & 13 & + & Normal & Liver & No & 0 & 0 \\
6 & 31 & +++ & Macerated & Liver & No & 0 & 0 \\
7 & 39.5 & + & Normal & Lung & No & 0 & 0 \\
8 & 16 & ++ & Macerated & Liver & $?$ & 0 & 0 \\
9 & 15 & + & Odematous & Lung & $?$ & +++ & +++ \\
10 & 22 & +++ & Hydrops & Liver & $?$ & +++ & ++ \\
11 & 11 & +++ & Macerated & Liver & $?$ & +++ \\
12 & 13 & ++ & Macerated & Lung & $?$ & ++ & ++ \\
13 & 17 & + & Normal & Kidney & No & +++ & 0 \\
14 & 17 & + & Hydrops & Kidney & Yes & +++ & 0 \\
15 & 14 & +++ & Hydrops & Liver & Yes & ++ & ++ \\
16 & 13 & ++ & Hydrops & Liver & $?$ & ++ \\
17 & 28 & +++ & Hydrops & Liver & Yes & ++ \\
18 & 36 & +++ & Macerated & Liver & Yes & ++ \\
19 & $14-17$ & +++ & Mummified & Kidney & No & +++ \\
\hline
\end{tabular}

Extent of maceration: + , mild changes in cytoplasm; ++ , nuclear lysis, some nuclei still recognisable; +++ , all nuclei unrecognisable. ISH and immunocytochemical results: 0 , no staining; +, weak staining; ++, acceptable staining; +++, excellent staining. $\star$ Tissue(s) other than the tissue tested for parvovirus B19 showed viral inclusions.

VI, Viral inclusion bodies; ?, equivocal viral inclusions.

Cases 5 to 7 were negative controls, showing no evidence of inclusions in any tissue, and having no associated appearance suggestive of intrauterine infection.

Case 13 was also selected as a negative control but for reasons discussed below, was changed to a test case.

Cases 8 to 12 were selected as showing appearances that fell some way short of diagnostically identifiable inclusions on haematoxylin and eosin stained sections of the tissue examined.

Cases 14 to 19 were selected because either inclusions were present but very scanty in the better preserved other tissues from the same cases (table 1) or, in the absence of inclusions, there was other suggestive histological evidence of a diffuse intrauterine infection of some kind, possibly parvovirus. In all these cases no viral inclusions could be identified on haematoxylin and eosin stained sections of the tissue selected for immunocytochemistry and ISH.

The degree of maceration was defined as follows: + , minor cytoplasmic and nuclear changes; ++ , cytoplasmic dissolution; +++ , partial nuclear and total cytoplasmic disruption.

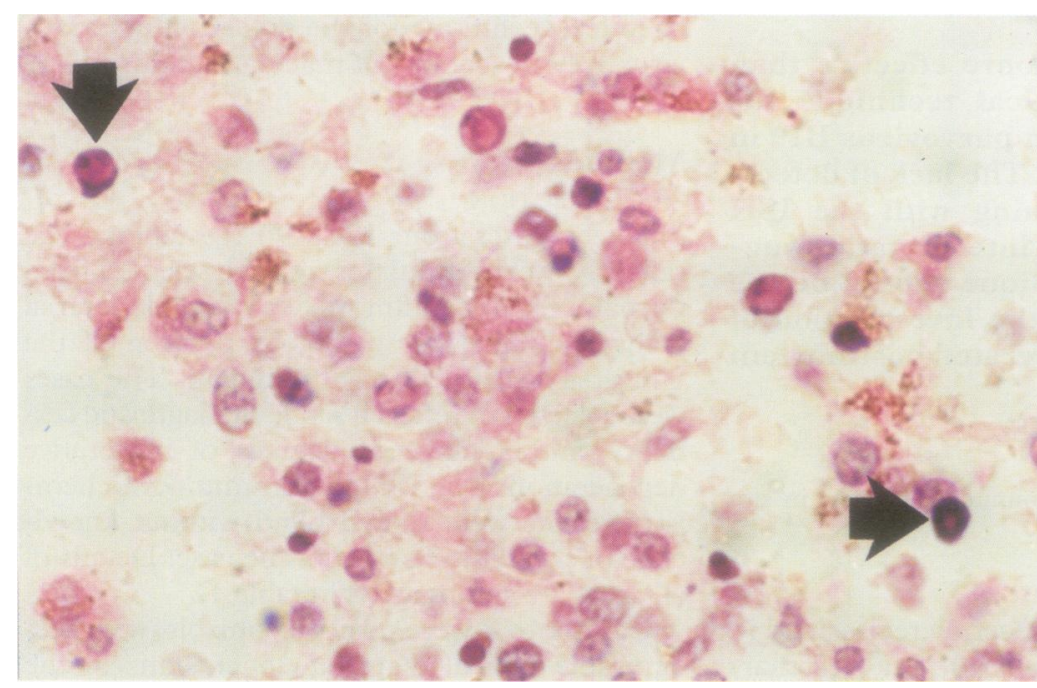

Figure 1 Section of macerated fetal liver showing viral inclusion bodies (arrows). (Counterstain: haematoxylin and eosin; original magnification $\times 63$ ).
IN SITU HYBRIDISATION

The parvovirus B19 clone (kindly provided by Dr Cohen, Colindale), consisted of the full viral genome of $5.5 \mathrm{~kb}$ attached to EcoR1 linkers and cloned by ligation into the EcoR1 site of a PGEM-1 vector. EcoR1 restricted DNA was labelled by random primed incorporation of digoxigenin labelled dUTP using a digoxigenin DNA labelling kit (Boehringer Mannheim, Lewes, East Sussex, UK) according to the manufacturer's instructions.

The ISH method used was according to Morey et al with some modifications. ${ }^{12}$ Sections ( $4 \mu \mathrm{m}$ thick) of paraffin processed tissue were cut and mounted on $1 \%$ aminopropyltriethoxysilane coated slides and baked at $60^{\circ} \mathrm{C}$ overnight. After dewaxing, the sections were digested in $0.1 \%$ pepsin (Sigma, Poole, Dorset, $\mathrm{UK}) / 0.01 \mathrm{M} \mathrm{HCl}$ for 30 minutes at $37^{\circ} \mathrm{C}$. The probe was diluted to $100 \mathrm{ng} / \mathrm{ml}$ in hybridisation fluid comprising $0.1 \%$ sodium dodecyl sulphate (Sigma), $10 \mathrm{mg} / \mathrm{ml}$ polyvinylpyrrolidone (Sigma), 10\% dextran sulphate, and $60 \%$ deionised formamide (Sigma). The tissue sections and probe mixture were simultaneously denatured at $95^{\circ} \mathrm{C}$ and chilled at $4^{\circ} \mathrm{C}$ before hybridisation. Following detection of bound probe using anti-digoxigenin (alkaline phosphatase) conjugate (Boehringer Mannheim) sections were visualised using NBT/ BCIP.

Negative controls omitting the parvovirus B19 probe were included with each experiment. Additionally, a known positive parvovirus B19 tissue section (kindly provided by $\mathrm{Dr}$ Fleming, Oxford) was included. One of the ISH positive parvovirus B19 cases was hybridised with a digoxigenin labelled herpes simplex virus 2 probe (Kreatech Diagnostics, Amsterdam, The Netherlands) according to the manufacturer's instructions, to confirm the specificity of the parvovirus B19 probe. Ten cases showing no serological or histological evidence of parvovirus B19 were also included as negative controls. 


\section{IMMUNOCYTOCHEMISTRY}

Sections ( $4 \mu \mathrm{m}$ thick) of paraffin processed tissue adjacent to those used for the ISH study were mounted on poly-l-lysine coated slides
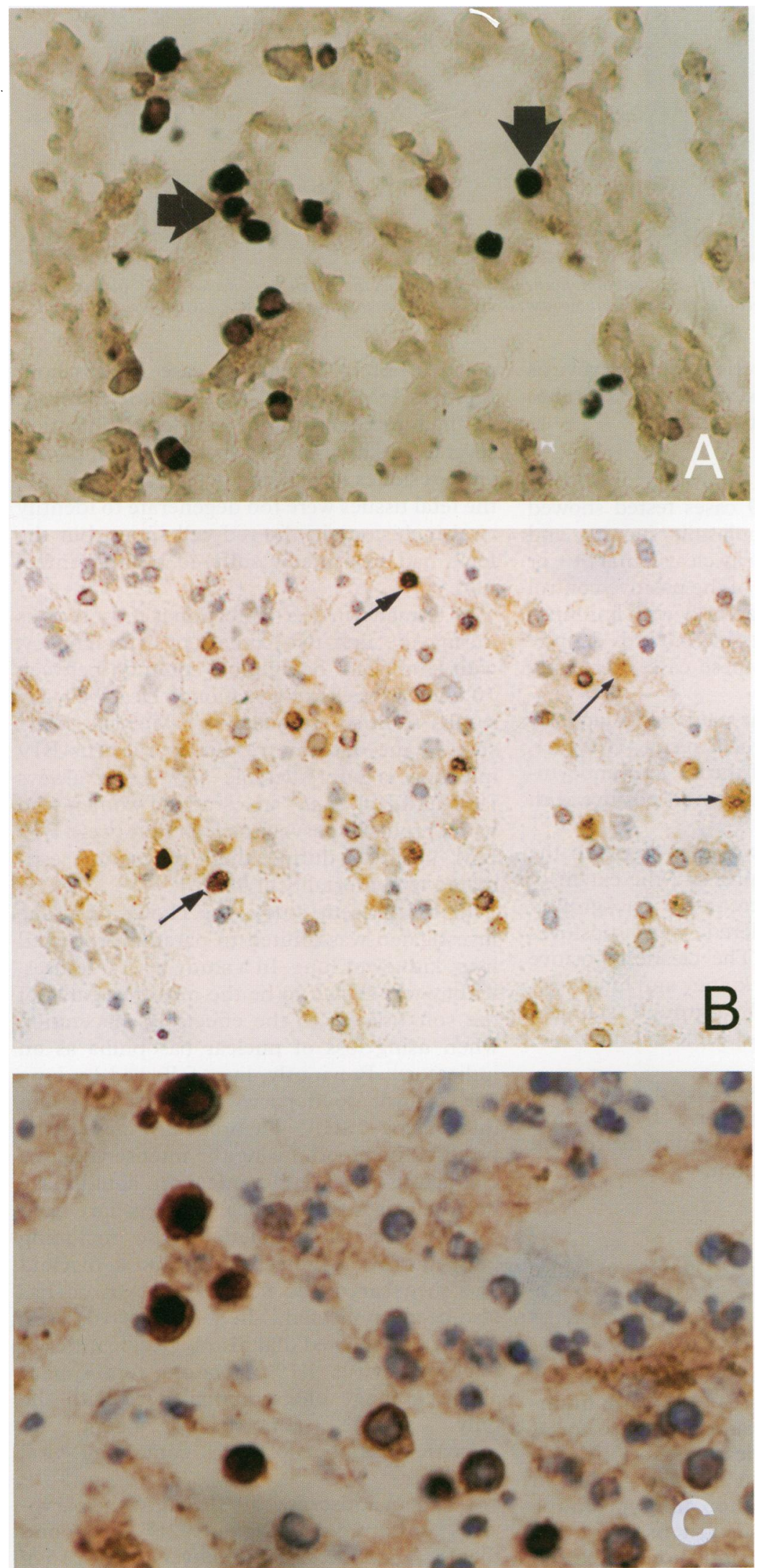

Figure 2 Comparison of ISH and the immunochemical technique for parvovirus B19 on replicate sections of fetal liver tissue. Note the improved contrast and strong black staining of the infected cells (arrows) with the ISH probed section (A). The immunostained section (B) shows reduced contrast of the positive cells (large arrows) due to increased background staining (small arrows). An example of clearer immunostaining is seen in (C). (Counterstain: immunochemistry, haematoxylin; original magnification $\times 63$.) and dried overnight at $37^{\circ} \mathrm{C}$. A three-step avidin-biotin complex immunocytochemical technique was performed according to Hsu et $a l^{13}$ to detect the parvovirus B19 antigen. The dilution of the primary antiserum, monoclonal parvovirus B19 antiserum (Clone R92F6; Novacastra, Newcastle, UK), was optimised to produce the strongest signal with minimal background staining, using the same positive control tissue block used for the ISH technique. Final dilutions of $1 / 50$ and 1/500 were used for the monoclonal parvovirus B19 antiserum and biotinylated rabbit antimouse antiserum (Dako, High Wycombe, Bucks, UK), respectively, in 1/20 non-immune swine serum/Tris buffered saline. A horse radish peroxidase conjugated avidin-biotin complex (Dako) was used according to the manufacturer's instructions and visualised using diaminobenzidine tetrahydrochloride.

Controls comprised omission of the primary (B19) antiserum and a known positive parvovirus B19 section. Ten cases known not to contain parvovirus were also included as negative controls.

\section{Results}

IN SITU HYBRIDIZATION

The results are shown in table 1 . Of the 19 cases investigated 15 gave positive results with the parvovirus B19 probe. All positive cases (1-4), showing definite nuclear viral inclusions in the index tissue with the haematoxylin and eosin stains (fig 1), stained positive by ISH. Cases 5-7 (negative controls), showed no evidence of ISH staining. One of the cases initially selected as a negative control (case 13) showed strong ISH staining. A detailed reexamination of all the tissue stained with haematoxylin and eosin was carried out and no hint of viral inclusions was seen. Four of the five cases selected for possible presence of inclusions (cases 8-12) were positive with ISH. Cases 14-19 showed no identifiable viral inclusions in the tissues examined but either showed inclusions elsewhere, or suggestive autopsy appearances were B19 ISH positive. Overall, six of the positive cases were in severely macerated tissue, three in moderately macerated tissue, and six in mildly macerated tissue (table 1). Almost all ISH positive cases showed excellent staining with low background irrespective of extent of maceration, compared with a large amount of background staining shown by many of the immunocytochemical stains of the same tissue (figs $2 \mathrm{~A}$ and 2B). Strong staining was found in all tissue types tested: liver, followed by lung, showing the most abundant parvovirus B19 infected cells. Within the liver, positive cells were found relatively evenly spread through the sinusoids with strong signals in erythroblasts contained within vessels. Staining in lung tissue was mainly localised to cells in the interstitium, while staining in the kidneys was mainly localised to trapped blood cells within the glomeruli.

The negative controls showed no staining with the ISH technique. The positive B19 control sample showed strong staining distributed 

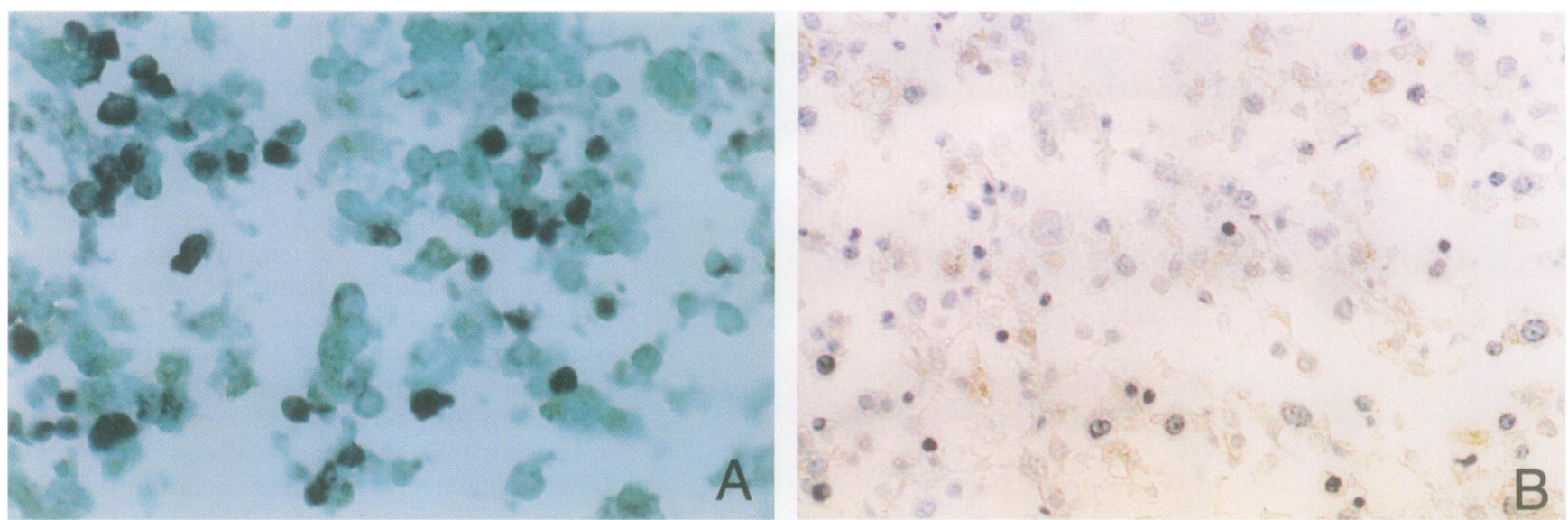

Figure 3 Replicate sections of case 4 treated for parvovirus B19 ISH $(A)$ and immunochemistry (B) showed the presence of infected cells (black staining) with the ISH but an absence of staining with the immunochemical technique. (Counterstain: ISH, Fast Green; immunochemistry, haematoxylin; original magnification $\times 63$.)

throughout the tissue section. The parvovirus $\mathrm{B} 19$ and herpes simplex virus type 2 probes showed no cross reactivity.

\section{IMMUNOCYTOCHEMISTRY}

Overall, only eight of 19 cases tested showed any positive brown cytoplasmic staining and only five gave a satisfactorily clear signal $(++$ or +++ ) (fig 2C). Only one of the positive control cases (1-4) stained satisfactorily with immunocytochemistry, although all showed definite viral inclusions. Two of these cases were only weakly positive $(+)$.

In cases 9-19, only four stained satisfactorily positive, with one equivocal result. However, these cases and all six of the 11 immunocytochemically negative cases proved positive with ISH (fig 3; table 1).

No clear correlation was seen between the strength of immunostaining and the extent of maceration, but the increase in background debris may have rendered weak positives unidentifiable (fig 2B). The cleanest positive results were found in the kidney and lung, with liver giving the most background staining, appearing as brown non-specific immunoreactivity.

The negative control samples did not show specific staining. The positive B19 control sample gave clear positive staining distributed throughout the tissue section.

\section{Discussion}

Parvovirus B19 infection is known to cause hydrops fetalis, ${ }^{9}$ increasing the risk of fetal loss in women with acute infection by $5-20 \%{ }^{8}$ Nine of our cases were hydrops fetalis. Parvovirus is also known to cause spontaneous abortion. ${ }^{14}$ One of our cases (19) was a mummified fetus probably retained in utero for at least three weeks after death. Also, one case (13) gave strong signals in appropriate cells in an appropriate tissue location and type, in the absence of any viral inclusions or other evidence of hydrops or infection. Archived serum from the TORCH screen samples for these cases were located in the $-70^{\circ} \mathrm{C}$ storage, and retrospective IgG and $\operatorname{IgM}$ tests for parvovirus antibody were carried out at Colindale reference laboratory. Case 13 was IgG positive but IgM negative, case 19 was both IgG and IgM positive. We conclude that case 13 had recovered from sub-lethal infection several weeks earlier and that persistent parvovirus residues were being detected. In case 19, the fetal tissues were too degenerate to identify viral inclusions in the red cell series, but the fetus had most likely suffered a lethal infection.

In humans, in utero infection is most serious during the first two trimesters of pregnancy, with fetal death being most common between 10 and 20 weeks of gestation. ${ }^{15}$ Death usually results from severe anaemia. ${ }^{16}$ Woernle et al ${ }^{8}$ showed the outcome of fetal parvovirus B19 infection is unpredictable and is not always fatal, and Hall et al, ${ }^{10}$ in a study of women who had a probable parvovirus infection (were B19 IgM positive) during their pregnancy, estimated fetal mortality at $9 \%$.

In the present study, the choice of tissue investigated was limited to paraffin processed liver, kidney or lung. In a study of 100 fetuses, kidney was shown to be the most resistant (of the soft tissues) to the effects of maceration when using loss of nuclear basophilia as an indicator. ${ }^{17}$ Previously, liver followed by lung have shown good parvovirus B19 detection rates using ISH. ${ }^{12}$ Theoretically, any tissue perfused by blood during the intense viraemia characteristic of early infection could have been selected. Pathological changes have been reported in haemopoietic tissue including bone marrow aspirates, ${ }^{18}$ liver, ${ }^{9}$ and in myeloid and megakaryocytic cells, ${ }^{11}$ heart tissue has also been implicated. ${ }^{19}$ In a study of 10 cases, Morey et al showed that histological features of fetal parvovirus B19 infection were similar across a range of gestational ages with the only notable abnormality being an increased number of cells containing viral inclusions. $^{20}$

Using an antiserum raised against the parvovirus capsid protein (Clone R92F6), we found that ISH gave increased effectiveness with 15 of 19 cases being B19 genome positive compared with eight of 19 cases using immunocytochemistry. In a previous study, Porter et al demonstrated parvovirus B19 using ISH in four of 13 cases, two of which showed maceration, leading 
the authors to suggest that the incidence of infection may be more common than is generally thought. ${ }^{9}$

All four of the definite positives for viral inclusion bodies on the haematoxylin and eosin stained sections were positive with ISH, but only three of four were positive by immunocytochemistry. Only one case (8) with dubious eosinophilic inclusions turned out to be negative by both ISH and immunocytochemistry. None of the remaining $11 \mathrm{ISH}$ positive cases showed definite viral inclusions in the tissues tested but four cases showed inclusions when haematoxylin and eosin stained sections of other tissue samples were examined retrospectively (table 1). Only two cases showed excellent immunocytochemical staining with a further three showing acceptable or weak staining.

An ISH signal was seen in six of seven of the severely macerated cases compared with three of seven using immunocytochemical staining; with the exception of one case (11), the immunocytochemical staining was inferior to that seen with the ISH. These findings suggest that ISH is more effective than immunocytochemistry at detecting parvovirus B19 in macerated tissues, in agreement with the study of Morey $e t$ $a l^{21}$ In the latter study, there was no significant difference in the detection rate between ISH and immunochemistry in optimally preserved tissues; however, an association between decreased immunochemical sensitivity and macerated tissues was observed.

The improved detection rate with ISH may in part result from a much clearer signal seen against virtually no background staining. In comparison, the immunocytochemically stained sections, especially in macerated liver, showed a serious increase in background staining. This is possibly due to binding of the avidin-biotin complex (used for detection) to endogenous biotin, or cross reactivity of the antisera with protein moieties. ${ }^{22}$ The negative control sections also showed background staining. Blocking of endogenous biotin may improve staining quality, but it is unlikely that the positive detection rate would rise significantly as the degree of cellular disruption in macerated tissue precludes identification of the precise intracellular location of the positively stained material.

The method of detection for parvovirus B19 is dependent on the timing of the diagnosis. Clinically recent infections can be detected using serology, ${ }^{23}$ while for macerated postmortem tissues, the choices of detection are narrowed. More sensitive assays rely on detection using dot blot or polymerase chain reaction (PCR) techniques but these may produce false positive results with fixed tissues, which are likely to be examined in a histopathology department. Reliable extraction methods require optimisation, and PCR equipment is not always available. In a recent study of six parvovirus B19 positive fetuses using PCR, five cases were positive by immunochemistry and ISH. ${ }^{24}$ However, the in situ and immunochemistry techniques were negative on a different case suggesting the need for caution if using only one of these techniques. The B19 genome is rich in cytosine-guanosine content, conferring good nuclear stability due to strong secondary structure ${ }^{10}$; this probably endows the genome with its resistance to degradation in macerated fetal tissues whereas the B19 protein coat seems be more susceptible.

In this study, we have shown ISH to be more sensitive than immunocytochemistry for the detection of parvovirus B19 in fixed, paraffin processed blocks of macerated fetal tissue. Although liver usually shows more advanced maceration than other tissues, excellent staining was achieved with ISH suggesting the parvovirus B19 genome is resistant to the effects of tissue maceration. The use of less susceptible tissue also gave good results. We therefore recommend ISH for the detection of parvovirus infection in macerated fetal tissue.

We thank Dr K A Fleming of the John Radcliffe Hospital, Oxford, for his advice and Dr B J Cohen of the Viral Reference Centre, Colindale, for supplying the B19 parvovirus clone. Thanks are due to Miss Anne Kane for her photographic assistance.

Pringle CR. Virus taxonomy update. Taxonomic decisions ratified at the plenary meeting of the ICTV at the 9th international congress of virology held in Glasgow on the 10th August 1993. Arch Virol 1993;133:491-5.

2 Cossart YE, Field AM, Cant B, Widdows D. Parvovirus like particles in human sera. Lancet 1975;i:72-3.

3 Summers J, Jones SE, Anderson MJ. Characterization of the genome of the agent of erythrocyte aplasia permits its classification as a human Parvovirus. F Gen Virol 1983;64 25-7.

4 Young N. Haematolgic and haematopoietic consequences of B19 Parvovirus infection. Semin Hemoto 1988;25:59172 .

5 Serjeant GR, Serjeant BE, Thomas PW, Anderson MJ, Patou G, Pattison JR. Human parvovirus infection in
homozygous sickle-cell disease. Lancet 1993;341:123740.

6 Anderson MJ, Jones SE, Fisher-Hoch SP. Human parvovirus the cause of erythema infectiosum (fifth disease) [letter]. Lancet 1983;i:1378.

7 Berry PJ, Gray ES, Porter HJ, Burton PA,. Parvovirus infection of the human fetus and newborn. Semin Diagn Patho 1992;9:4-12

8 Woerlne $\mathrm{CH}$, Anderson LJ, Tattersall P. Human parvovirus during pregnancy. $\mathcal{F}$ Infect Dis 1987;156:17-20.

9 Porter HJ, Khong TY, Evans MF, Chan VTW, Fleming KA Parvovirus as a cause of hydrops fetalis, detection by in-situ DNA hybridization. 7 Clin Pathol 1988;41:381-3.

10 Hall SM, Cohen BJ, Mortimer PP, Anderson MJ, Pattison JR, Shirley JA, et al. Prospective study of human JR, Shirley JA, et al. Prospective study of human parvovirus

11 Kubat M, Gusic S, Martinovic S, Zecevic D. Identification of human remains using DNA isolated from bones stored under various conditions and for different post mortem times. Croatian Medical fournal 1996;37:214-16.

12 Morey AL, Porter HJ, Keeling JW, Fleming KA. Nonisotopic in-situ hybridisation and immunophenotyping of infected cells in the investigation of human fetal Parvovirus infection. F Clin Pathol 1992;45:673-8.

$13 \mathrm{Hsu}$ SM, Raine L, Fanger H. Use of avidin-biotinperoxidase complex (ABC) in immunoperoxidase peroxidase complex (ABC) in $\mathrm{ABm}$ unoperoxidase techniques; a comparison between ABC and unlabelled antibody

14 Brown T, Anand A, Richie LD, Clewley JP, Ried TMS International parvovirus infection associated with hydrops fetalis. Lancet 1984;ii: $1033-4$

15 Centres for disease control. Risk associated with human parvovirus B19 infection. MMWR Morb Mortal Wkly Rep 1989;38:81-97.

16 Anderson LJ, Hurwitz ES. Human parvovirus B19 and pregnancy. Clin Perinatal 1988;15:273-86.

17 Genest DR, Williams MA, Greene MF. Estimating the time of death in stillborn fetuses: I. Histologic evaluation of fetal organs; an autopsy study of 150 stillborns. Obstet Gynecol 1992;80:575-84.

18 Kertzman GJ, Ozawa K, Cohen B. Chronic bone marrow failure due to persistent $\mathrm{B} 19$ parvovirus infection. $N \mathrm{Engl} \mathcal{F}$ Med 1987:317:287-92. 
19 Porter HJ, Quantrill AM, Fleming KA. B19 Parvovirus infection of myocardial cells [letter]. Lancet 1988;i:535-6.

20 Morey AL, Keeling JW, Porter HJ, Fleming KA Clinical and histopathological features of parvovirus B19 infection in the human fetus. F Obstet Gynaecol 1992;99. 566-74.

21 Morey AL, O’Neill HJ, Coyle PV, Fleming KA. Immunohistological detection of human parvovirus B19 in formalin-fixed, paraffin-embedded tissues. $\mathcal{F}$ Pathol 1992 166:105-8
22 Wood GS, Warnke R. Suppression of endogenous avidin/ biotin activity in tissues and its relevance to biotin avidin detection systems. F Histochem Cytochem 1981;29:1196-

23 Cohen BJ, Mortimer PP, Pereira MS. Diagnostic assays with monoclonal antibodies for human serum parvovirus-like virus (SPLV). Fournal of Hygiene 1983;91:113-30.

24 Jordan JA. Identification of human parvovirus B19 infection in idiopathic nonimmune hydrops fetalis. $\mathrm{Am} 7 \mathrm{Obstet}$ Gynecol 1996;174:37-42. 